\title{
9. DATA REPORT: SECONDARY MINERALS IN HOLE 864A ${ }^{1}$
}

\author{
Rachel M. Haymon²
}

\section{INTRODUCTION}

The presence and abundance of secondary minerals in Ocean Drilling Program Hole 864A cores record the earliest stages in the geochemical/ mineralogical alteration of nascent oceanic crust and indicate the rapidity of hydrothermal alteration and crack sealing at mid-ocean ridges. Hole 864A was drilled in the axial summit caldera (ASC) of the East Pacific Rise (EPR) at $9.5^{\circ} \mathrm{N}$ into basaltic ocean crust that is probably less than $500 \mathrm{yr}$ old (Haymon et al., 1991). Core recovered from the hole shows initiation of ocean crust alteration and crack sealing from hydrothermal mineral precipitation. Hole $864 \mathrm{~A}$ was spudded into a 2-to 3-m-thick massive flow of fresh basalt ("ODP Flow") that floors the ASC at $9^{\circ} 30^{\prime}-31^{\prime} \mathrm{N}$. Approximately $2 \%-4 \%$ of the basalt fragments recovered from beneath this capping flow, in Unit I, Sections 5 and 6, exhibit secondary hydrothermal precipitates that occur as white, greenish, creamy, and orange surficial encrustations on glassy surfaces and as fillings of microcracks and vesicles. Phases present include very fine-grained silicate, oxide, and possible sulfide minerals. Because of the fine-grained nature of the precipitates and their occurrence as very thin $(<50 \mu)$ encrustations on rock surfaces, it was not possible to identify specific minerals positively. Cursory shipboard microscopic examination of the precipitates suggested an assemblage composed of unspecified phyllosilicate minerals, iron oxyhydroxides, opaline silica, possible quartz, and traces of possible $\mathrm{Fe}$ - and $\mathrm{CuFe}$-sulfide minerals. This data report is a preliminary description of the morphology and composition of the dominant phases present in the samples. Analyses in progress will provide complete descriptions and quantitative analysis of all of the phases present in the alteration assemblage.

\section{Description of Samples}

Twenty basalt fragments coated with precipitates representative of the different types of secondary minerals found in Hole 864A were subsampled from Sections 5 and 6 in cores from Unit I. In all cases, alteration is confined to surfaces, cracks, and vesicles and does not penetrate more than $100 \mu$ into the sample interiors. The alteration products appear to form either from reaction of glass or by direct precipitation from fluids, not from alteration of crystalline basalt. The resulting assemblage is dominated by minerals that are either whitish, greenish, or orange. The samples thus were split into "white," "green," and "orange" subgroups. Only the white and green groups are described here. (The orange group has not been adequately studied; however, these encrustations are expected to contain a large component of Fe-oxyhydroxide phase[s].) Pieces of white- and green-coated samples containing altered free surfaces, vesicle fillings, and microcrack fillings were selected for separate analysis to

\footnotetext{
${ }^{1}$ Batiza, R., Storms, M.A., and Allan, J.F. (Eds.), 1995. Proc. ODP, Sci. Results. 142: College Station, TX (Ocean Drilling Program).

${ }^{2}$ Department of Geology, University of California at Santa Barbara, Santa Barbara, CA 93106, U.S.A.
}

determine if physically distinct sites in the rock exhibit differences in alteration.

\section{ANALYTICAL METHODS}

Intact fragments of altered basalt glass were mounted on aluminum stubs, with careful attention paid to sample orientation so that free (exterior) surfaces could be distinguished during analysis from surfaces in the interiors of samples. The samples were carbon-coated and examined at high magnification using a JEOL JSM-840A scanning electron microscope (SEM) at the University of California, Santa Barbara. Qualitative chemical analyses of small $\left(100 \mu^{2}\right)$ areas on these samples were obtained by acquiring spectra over $60 \mathrm{~s}$ intervals with an X-ray energy dispersive system (EDS) attached to the SEM.

\section{RESULTS \\ Coatings of Exterior Surfaces}

The thin $(<50 \mu$ thick) coatings on the exterior free surfaces of glassy fragments exhibit complex layered morphologies (Fig. 1A and 1C). SEM photomicrographs in Figures $1 \mathrm{~A}$ and $1 \mathrm{C}$ show examples of well-developed multilayering in a green-colored coating. In general, the morphologies of the white and green coatings vary from sample to sample, but the two groups are not systematically different in morphology. The morphologies of these layered coatings resemble high-temperature phyllosilicate alteration assemblages identified on the glassy surfaces of basalt samples collected on the EPR crest at $21^{\circ} \mathrm{N}$ (Haymon and Kastner, 1986).

Examples of EDS analyses of the top (exterior) surfaces of the samples are shown in Figures 2 and 3. Noting that these surfaces were either smooth or "pilled" (see Fig. 1C), both surface types were analyzed (Figs. 2 and 3 ).

The EDS analyses confirm that the coatings are composed mainly of $\mathrm{Al}$ and $\mathrm{Si}$, with varying amounts of $\mathrm{Mg}, \mathrm{Ti}$, and $\mathrm{Fe}$. The composition of smooth and pilled tops on the same samples are virtually identical (Figs. 2 and 3). The green material (Fig. 2, top two spectra) has somewhat more silica than alumina, contains significant amounts of $\mathrm{Fe}$ and $\mathrm{Mg}$, and is probably composed largely of Fe-rich smectite, chlorite, and/or an interlayered chlorite-smectite phase. The white material (Fig. 2, bottom spectra), however, is very aluminous and lacks divalent cations. Because the $\mathrm{Si} / \mathrm{Al}$ ratio is so low, it seems unlikely that this is an aluminous clay mineral such as kaolinite or dickite. The analyses indicate that this material is largely an Aloxyhydroxide such as diaspore or boehmite, plus some amorphous silica or minor component of kaolinite or dickite.

\section{Microcrack Fillings}

The morphology of creamy white material lining small microcracks in glassy rinds is exemplified by the photomicrograph in Figure 1D. This material exhibits poorly developed layering and top surfaces that are both smooth and pilled. 


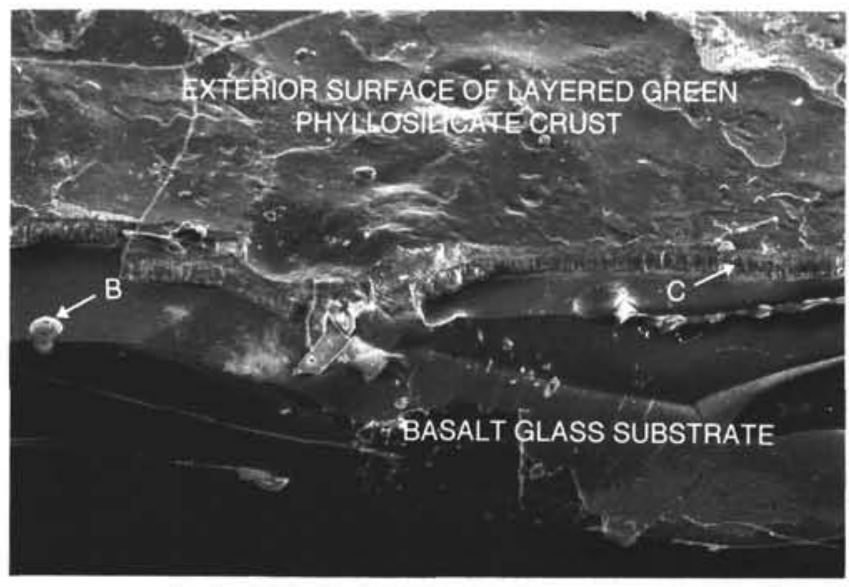

A

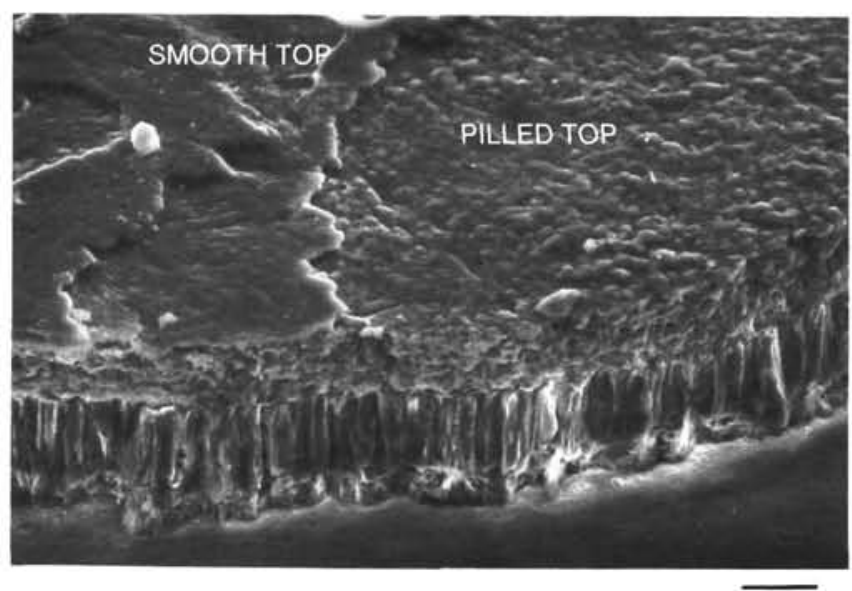

C

100 microns
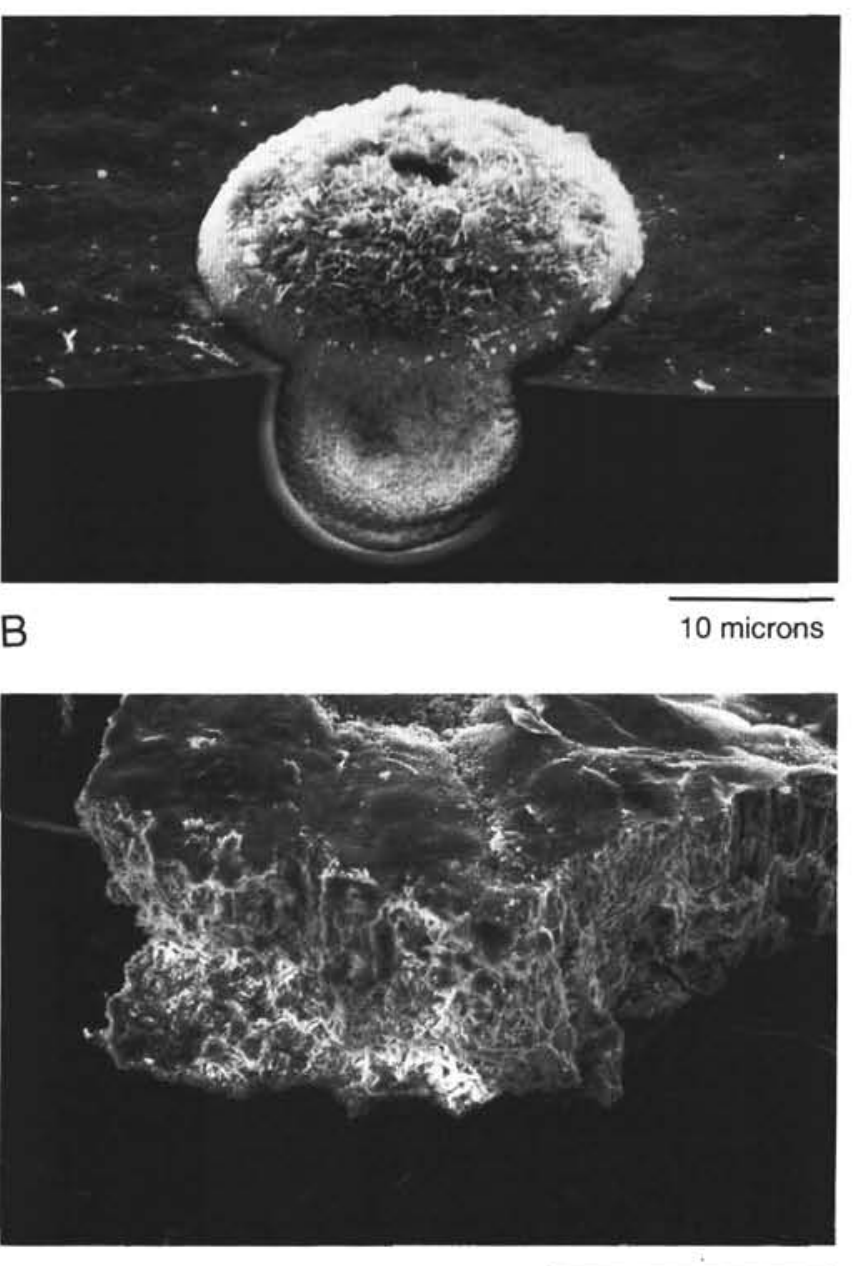

100 microns

Figure 1. SEM photomicrographs of alteration products in Hole 864A samples from Unit I core, Sections 5 and 6 (beneath ODP Flow). A. Large-scale photo of a thin, greenish, secondary mineral coating on the exterior surface of a basaltic glass fragment. Locations of higher magnification photos (B and C) are indicated by arrows. B. Three-dimensional view of a vesicle filled with a secondary mineral exhibiting the morphology of smectite (Cann et al., 1977; Hajash and Archer, 1980). C. Close-up photo of the layered morphology of typical green and white coatings on the exterior surfaces of basalt fragments. Note that the "top" (exteriormost) surface exhibits two morphologies: smooth and "pilled." D. Photo of the creamy white secondary crust that lines a microcrack in glass. The material was carefully detached from the glass and has been placed on the stub so that the interior surface (surface that was in contact with basalt glass) is now in contact with the stub. Note that layering in this material is poorly developed.

EDS analyses of crack fillings are shown in Figure 3. The variation in morphology of the top surfaces (smooth vs. pilled) does not correspond to any detectable compositional difference. Comparing the composition of the crack fillings (Fig. 3) with that of the green exterior surface coatings described above (Fig. 2, top two spectra), one can see that these materials are similar but not identical. The crack linings have higher $\mathrm{Si} / \mathrm{Al}$ and $\mathrm{Mg} / \mathrm{Fe}$ ratios than the exterior surface coatings and probably have a higher component of magnesian smectite than the exterior surface coatings.

\section{Vesicle Fillings}

The vesicle fillings in these samples exhibit the "cornflakes" habit typical of smectite (Cann et al., 1977; Hajash and Archer, 1980).

This identification is consistent with the EDS spectra (Fig. 2, third spectra from top), which indicates a composition similar to that of the microcrack fillings described above. These vesicle fillings have a higher $\mathrm{Si} / \mathrm{Al}$ and $\mathrm{Mg} / \mathrm{Fe}$ ratio than the exterior surface coatings (Fig. 2 , top two spectra).

\section{SUMMARY OF RESULTS}

Beneath the cap of lava formed by the ODP Flow, reaction of basaltic glass and direct precipitation of minerals from saturated fluids has quickly produced secondary mineral assemblages that are dominated by $\mathrm{Fe}-\mathrm{Mg}$ phyllosilicates, $\mathrm{Al}$-oxyhydroxides, and $\mathrm{Fe}$-oxyhydroxides (not discussed here). These assemblages coat exposed surfaces, fill voids (cracks and vesicles) in the rock, and constitute $\sim 2 \%-4 \%$ of the rock by volume. Because intact cores were not recovered, it is difficult to estimate the percentage of pore space that has been filled in the short time since the basaltic flows drilled in Hole 864 A were erupted. Submersible observations in March, 1992, confirmed that low temperature hydrothermal vents, found in 1989 and 


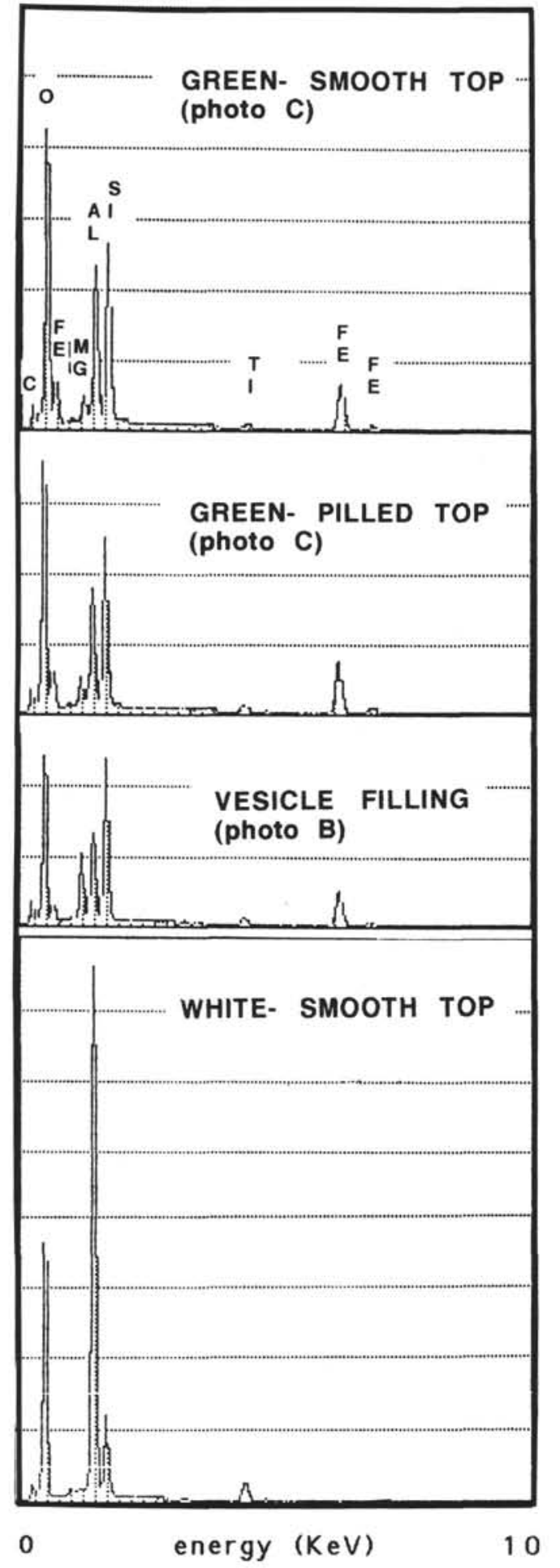

Figure 2. EDS spectra comparing compositions of green and white exterior surface coatings with smooth and pilled tops, as indicated, to the composition of vesicle fillings.

located 50 to $100 \mathrm{~m}$ north of Hole $864 \mathrm{~A}$, were still active at the time of drilling. Active high-temperature (black smoker) discharge was observed by the author in 1991 in the ASC $~ 700 \mathrm{~m}$ north of Hole $864 \mathrm{~A}$, and extinct sulfide deposits are located within $500 \mathrm{~m}$ of the drill site (Haymon et al., 1991). These observations, plus the similar morphologies and compositions of the Hole $864 \mathrm{~A}$ assemblages with

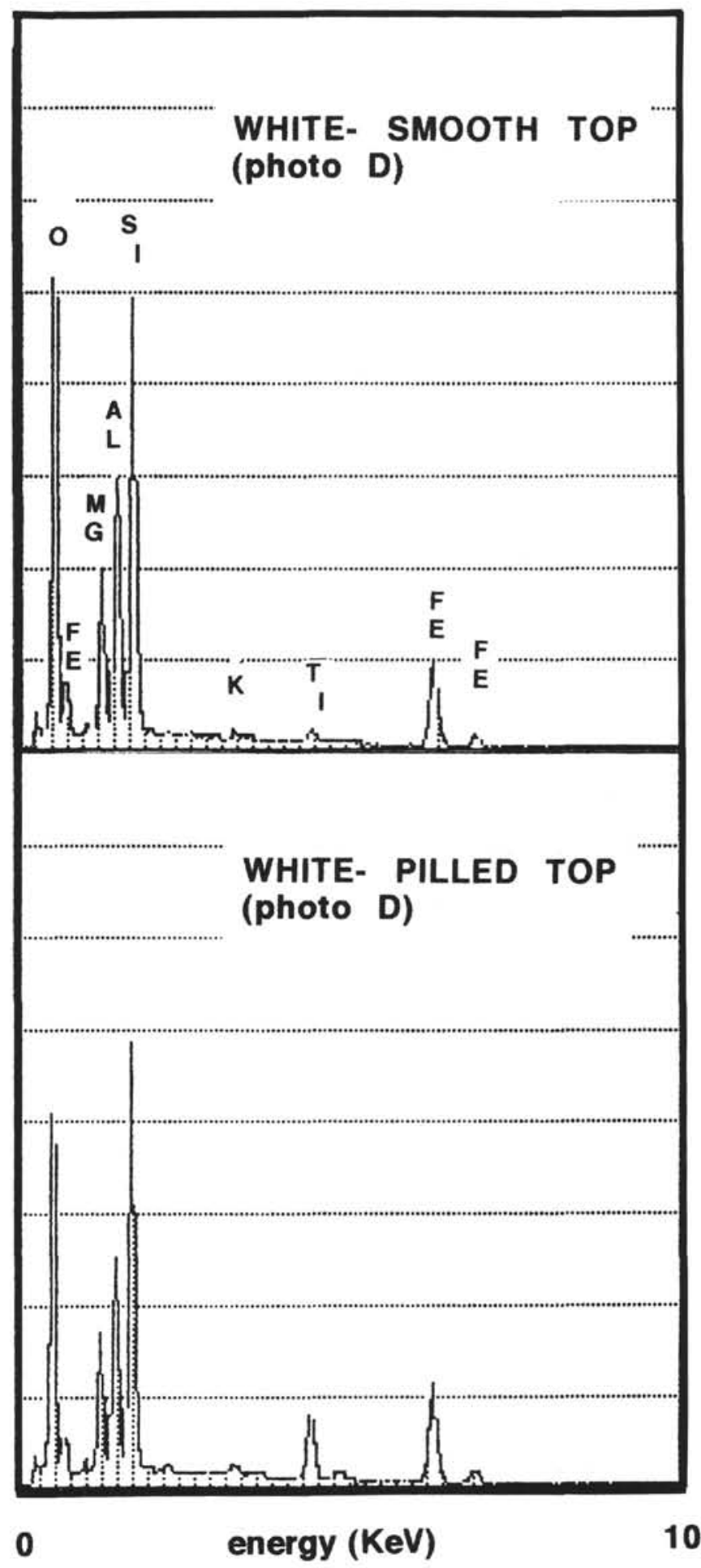

Figure 3. EDS spectra comparing the compositions of smooth and pilled areas on the top surface of creamy white material that lines a microcrack in a glassy flow rind.

EPR, $21^{\circ} \mathrm{N}$ assemblages of certain hydrothermal origin (Haymon and Kastner, 1986), support the hypothesis that the secondary minerals in Hole $864 \mathrm{~A}$ have formed mainly from reaction of hydrothermal fluids with basaltic glass.

The alteration products formed on free exterior surfaces are typically multilayered crusts that range in composition from $\mathrm{Fe}-\mathrm{Mg}$ phyl- 
losilicates (smectite, chlorite, and/or mixed layer smectite-chlorite) to Al-oxyhydroxides (diaspore or boehmite). The fact that the morphologies of the phyllosilicate crusts are not systematically different from the Al-oxyhydroxide crusts suggests that one is pseudomorphing the other. The layered nature of the encrustations suggests that the phyllosilicates may have formed first and been subsequently pseudomorphed by Al-oxyhydroxide. This would be consistent with decreasing $\mathrm{pH}$ in the circulating fluids over time. Howard and Fisk (1988) suggest a similar mode of formation for boehmite identified in encrustations of basalt samples from the northern Gorda Ridge. The vesicles and microcracks contain mainly magnesian smectite. This compositional difference, compared with the exterior surface crusts, may reflect a difference in formation mechanism (direct precipitation from fluids onto glass substrate, rather than reaction of glass substrate with fluids), or it may reflect a difference in the timing of mineral formation (either earlier or later than formation of the exterior surface crusts).

Electron microprobe analyses of the alteration products from Hole $864 \mathrm{~A}$ will be done in the near future to obtain quantitative data about their compositions and specify more precisely the phases present.

\section{REFERENCES}

Cann, J.R., Winter, C.K., and Pritchard, R.G., 1977. A hydrothermal deposit from the floor of the Gulf of Aden. Mineral. Mag., 41:193-199.
Hajash, A., and Archer, P., 1980. Experimental seawater/basalt interactions: effects of cooling. Contrib. Mineral. Petrol., 75:1-13.

Haymon, R.M., Fornari, D.J., Edwards, M.H., Carbotte, S.M., Wright, D., and Macdonald, K.C., 1991. Hydrothermal vent distribution along the East Pacific Rise crest $\left(9^{\circ} 09^{\prime}-54^{\prime} \mathrm{N}\right)$ and its relationship to magmatic and tectonic processes on fast-spreading mid-ocean ridges. Earth Planet. Sci. Lett., 104:513-534.

Haymon, R.M., and Kastner, M., 1986. The formation of high temperature clay minerals from basalt alteration during hydrothermal discharge on the East Pacific Rise axis at $21^{\circ} \mathrm{N}$. Geochim. Cosmochim. Acta, 50:1933-1939.

Howard, K.J., and Fisk, M.R., 1988. Hydrothermal alumina-rich clays and boehmite on the Gorda Ridge. Geochim. Cosmochim. Acta, 52:2269-2279.

Date of initial receipt: 11 October 1993

Date of acceptance: 6 May 1994

Ms 142SR-110

Abbreviations for names of organizations and publications in ODP reference lists fol-
low the style given in Chemical Abstracts Service Source Index (published by American Chemical Society). 